\title{
Towards a Better Understanding of Gold Electroless Deposition in Track-Etched Templates
}

\author{
M. De Leo, ${ }^{\dagger}$ F. C. Pereira, ${ }^{\ddagger}$ L. M. Moretto,${ }^{\dagger}$ P. Scopece, ${ }^{\S}$ S. Polizzi, ${ }^{\dagger}$ and P. Ugo ${ }^{*}, \dagger$ \\ Department of Physical Chemistry, University of Venice, S. Marta 2137, Venezia, Italy, Department of \\ Chemistry, Federal University of Rio Grande do Norte, 59072-970, RN, Brazil, and CIVEN, \\ Via della Libertà 12, 30175 Venezia Marghera, Italy
}

Received June 26, 2007. Revised Manuscript Received August 9, 2007

\begin{abstract}
The template method for preparing nanomaterials entails synthesis of tubular or fibrillar nanostructures within the pores of a microporous membrane. If the holes are completely filled, solid nanowires result, while a partial filling with a continuous coating gives rise to nanotubes. This paper focused on the study of the parameters controlling electroless gold deposition in track-etched polycarbonate membranes. The structure and morphology of the obtained nanomaterials are examined and compared by a variety of electron microscopies and atomic force microscopy and examined in relation to electrochemical and spectrophotometric results. As far as nanotubes are concerned, problems with obtaining such a nanostructure are observed, in particular when membranes with pore diameters equal to or smaller than $30 \mathrm{~nm}$ are used. In the case of nanowires, defects related to fabrication problems are evidenced when they are used to prepare nanoelectrode ensembles (NEEs), because defects dramatically influence their voltammetric behavior. The role of deposition time and $\mathrm{pH}$ on gold nucleation and growth is studied in detail. We demonstrate that these parameters indeed determine the formation of nanowires versus nanotubes. In all cases the deposit is started by the formation of gold nuclei on the walls of the previously activated membrane. Then the nuclei grow, until they are bound together to produce the final nanomaterial. A significantly better control of the deposition is achieved by separating the nuclei formation step from the growth process. At $\mathrm{pH} 10$ the nuclei growth is more regular but slower, whereas at $\mathrm{pH} 12$ the process is faster but their size distribution is wider. At $\mathrm{pH} 10$ the formation of nanotubes is better controlled, whereas at $\mathrm{pH} 12$ continuous nanofibers are more quickly formed.
\end{abstract}

\section{Introduction}

Deposition of metals ${ }^{1-8}$ and other materials ${ }^{9-12}$ in the pores of microporous membranes was introduced some years ago, quickly showing the suitability of this technique as a useful tool for the easy preparation of high aspect ratio nanomaterials. Among the different metals, gold is very often used to this aim because of its peculiar properties. Being a noble metal, gold possesses chemical inertness which makes it suitable for many

\footnotetext{
${ }^{\dagger}$ University of Venice.

* Federal University of Rio Grande do Norte.

$\$$ CIVEN.

(1) Ugo, P.; Moretto, L. M. In Handbook of Electrochemistry; Zosky, C. G., Ed.; Elsevier: Amsterdam, 2007; Chapter 16, Section 16.2, pp 678-709.

(2) Possin, G. E. Rev. Sci. Instrum. 1970, 41, 772.

(3) Williams, W. D.; Giordano, N. Rev. Sci. Instrum. 1984, 55, 410.

(4) Penner, R. M.; Martin, C. R. Anal. Chem., 1987, 59, 2625.

(5) Cheng, J. F.; Martin, C. R. Anal. Chem. 1988, 60, 2163.

(6) Menon, V. P.; Martin, C. R. Anal. Chem. 1995, 67, 1920.

(7) Uosaki, K.; Okazaki, K.; Kita, H.; Takahashi, H. Anal. Chem. 1990, $62,652$.

(8) Martin, C. R.; Mitchell, D. T. In Electroanalytical Chemistry, A Series of Advances; Bard, A. J., Rubinstein, I., Eds.; Marcel Dekker: New York, 1999; Vol. 21, pp 1-74.

(9) Lakshmi, B. B.; Patrissi, C. J.; Martin, C. R. Chem. Mater. 1997, 9 , 2544.

(10) Patrissi, C. J.; Martin, C. R. J. Electrochem. Soc. 1999, 146, 3176.

(11) Li, N.; Martin, C. R.; Scrosati, B. J. Power Sources 2001, 240, $97-$ 98.

(12) Che, G.; Jirage, K. B.; Fisher, E. R.; Martin, C. R.; Yoneyama, H. J.
} Electrochem. Soc. 1997, 144, 4296. biological and electrochemical applications. ${ }^{13-20}$ Moreover, the possibility to access to a variety of thiols makes the chemical functionalization of the surface of gold nanomaterials ${ }^{21-26}$ easy and flexible. Numerous examples of applications of gold nanodisks, nanofibers, or nanotubes are described in the recent

(13) Parthasarathy, R. V.; Martin, C. R. Nature 1994, 369, 298.

(14) Yu, S.; Lee, S. B.; Kang, M.; Martin, C. R. Nano Lett. 2001, 1, 495.

(15) Yu, S.; Lee, S. B.; Kang, M.; Martin, C. R. Anal. Chem. 2003, 75, 1239.

(16) Kohli, P.; Harrel, C. C.; Cao, Z.; Gasparac, R.; Tan, W.; Martin, C. R. Science 2004, 305, 984.

(17) Ugo, P.; Moretto, L. M.; Bellomi, S.; Menon, V. P.; Martin, C. R. Anal. Chem. 1996, 68, 4160.

(18) Brunetti, B.; Ugo, P.; Moretto, L. M.; Martin, C. R. J. Electroanal. Chem. 2000, 491, 166.

(19) Moretto, L. M.; Pepe, N.; Ugo, P. Talanta 2004, 62, 1055.

(20) De Leo, M.; Kuhn, A.; Ugo, P. Electroanalysis 2007, 19, 227.

(21) Bain, C. D.; Troughton, E. B.; Tao, Y.-T.; Evall, J.; Whitesides, G. M.; Nuzzo, R. G. J. Am. Chem. Soc. 1989, 111, 321.

(22) Dong, S.; Li, J. Bioelectrochem. Bioenerg. 1997, $42,7$.

(23) Jirage, K. B.; Hulteen, J. C.; Martin, C. R. Anal. Chem. 1999, 71, 4913.

(24) Martin, C. R.; Nishizawa, M.; Jirage, K. B.; Kang, M. J. Phys. Chem. B 2001, 105, 1925.

(25) Yu, J. S.; Kim, J. Y.; Lee, S.; Mbindyo, J. K. N.; Martin, B. R.; Mallouk, T. E., Chem. Commun. 2000, 2445.

(26) Mbindyo, J. K. N.; Reiss, B. D.; Martin, B. R.; Keating, C. D.; Natan, M. J. Adv. Mater. 2001, 13, 2445.

(27) Lee, S. B.; Mitchell, D. T.; Trofin, L.; Nevanen, T. K.; Soderlund, H.; Martin, C. R. Science 2002, 296, 2198.

(28) Mitchell, D. T.; Lee, S. B.; Trofin, L.; Nevanen, T. K.; Soderlund, H.; Martin, C. R. J. Am. Chem. Soc. 2002, 124, 11864.

(29) Lee, K. B.; Park, S.; Mirkin, C. A. Angew. Chem., Int. Ed. 2004, 43, 3048. 
literature, spanning from nanoelectrode ensembles to functionalized nanotubes for sophisticated molecular separations. ${ }^{27-29}$

Typically, the template is made by an insulating materials such as alumina, produced by anodic oxidation of aluminum in acidic conditions ${ }^{30-32}$ or track-etched polymers like polycarbonate (PC), polyethylenterephtalate (PET), or Kapton. ${ }^{6,33-35}$ Two methods of deposition of gold in the templates have been used, namely, electrochemical ${ }^{36-38}$ and electroless ${ }^{6,20}$ deposition. The former asks for the requirement of making one side of the templating membranes conductive; this is not always an easy task, particularly for continuity problems in the contact between the conductive layer and the template ${ }^{39}$ this causes lack of reproducibility, mainly for templates with pores of very small diameter (less than $100 \mathrm{~nm})^{1}$

As an alternative, an electroless deposition procedure, particularly suitable for gold deposition in microporous templating membranes, was developed ${ }^{6}$ and refined. ${ }^{40,41}$

Notwithstanding the many years of practice in the use of such an electroless procedure, the role of some key parameters on the final result of the deposition process has not been fully ascertained, in particular in controlling the formation of hollow nanotubes versus full nanofibers. Also the crystal habit and surface morphology of the obtained nanomaterials were not studied in detail.

In the case of nanofabrication of nanoelectrode ensembles (NEEs) for analytical and biosensing applications, ${ }^{6}$ where continuity of the metal fibers and absence of crevices are crucial, this lack of knowledge on the role of some deposition parameters can result in a lack of control on the characteristics and electrochemical behavior of the final NEE.

Very recently, Gilliam et al. ${ }^{42}$ reported the results of a study on nucleation and growth of $\mathrm{Au}$ in porous templates, mainly focused on nucleation and grain size distribution. However, the approach used was based on the classical methodology introduced by Menon and Martin in which ${ }^{6}$ the nucleation and growth of the Au particles overlap, with consequent difficulty in achieving a satisfactory control of

(30) Hornyak, G. L.; Patrissi, C. J.; Martin, C. R. J. Phys. Chem. B 1997, $101,1548$.

(31) Piao, Y.; Lim, H.; Chang, J. Y.; Lee, W.-Y.; Kim, H. Electrochim. Acta 2005, 50, 2997.

(32) Tian, M.; Xu, S.; Wang, J.; Kumar, N.; Wertz, E.; Li, Q.; Campbell, P. M.; Chan, M. H. W.; Mallouk, T. E. Nano Lett. 2005, 5, 697.

(33) Apel, P. Radiat. Meas. 2001, 34, 559.

(34) Siwy, Z.; Dobrev, D.; Neumann, R.; Trautmann, C.; Voss, K. German and U.S. Patent no. 10208 023.2, registration on February 26, 2002, Verfahren zur Herstellung von Nanostrukturen in Membranen und Asymmetrische Membran; Appl. Phys. A: Mater. Sci. Proc. 2003, 76, 781.

(35) Scopece, P., Ph.D Thesis, University of Venice, Venice, Italy, 2004.

(36) Schönenberger, C.; Zande, B. M. I. v. d.; Fokkink, L. G. J.; Henny, M.; Schmid, C.; Krüger, M.; Bachtold, A.; Huber, R.; Birk, H.; Staufer, U. J. Phys. Chem. B 1997, 101, 5497.

(37) Wang, J. G.; Tian, M. L.; Mallouk, T. E.; Chan, M. H. W. Nano Lett. 2004, 4, 1313.

(38) Payne, E. K.; Shuford, K. L.; Park, S.; Schatz, G. C.; Mirkin, C. A. J. Phys. Chem. B 2006, 110, 2150.

(39) Foss, J. C. A. In Metal Nanoparticles, Synthesis, Characterization and Aplications; Feldheim, D. L., Foss, J. C. A., Eds.; Marcel Dekker Inc.: New York, 2002; Chapter 5, pp 119-140.

(40) Jirage, K. B.; Hulteen, J. C.; Martin, C. R. Science 1997, 278, 655.

(41) Scopece, P.; Baker, L. A.; Ugo, P.; Martin, C. R. Nanotechnology 2006, 17, 3951 .

(42) Gilliam, R. J.; Thorpe, S. J.; Kirk, D. W. J. Appl. Electrochem. 2006, 37,233 . grain size. ${ }^{42}$ In our laboratory, by using the traditional procedure introduced by Menon and Martin, ${ }^{6}$ we observed that the percentage of NEEs that displayed their peculiar electrochemical behavior was typically around $30-40 \%$ for a batch of NEEs produced. ${ }^{43}$ Defective NEEs were affected by $^{1}$ (i) uncontrolled changes in the active area of the NEEs (in particular the number of nanodisks that compose the ensemble); (ii) uncontrolled increase of the background capacitive current; and (iii) failures in the electrical contact between the nanoelectrodes and the signal collector.

Electroless metal deposition involves the use of chemical reducing agents to plate a metal from a solution onto a surface. ${ }^{44}$ The key requirement for this process is to arrange the chemistry so that the kinetics of homogeneous electron transfer from the reducing agent to the metal ion be very slow. A catalyst that accelerates the rate of metal ion reduction is indeed applied to the surface to be coated. As a consequence, the metal ion is preferentially reduced at the surface so that only this part is coated with the desired metal.

In the case of gold electroless deposition, complete formation of the Au nuclei before the onset of the growth process could be crucial, because these nuclei act as catalytic sites for the following Au deposition, which occurs after the addition of formaldehyde as a reducing agent, according to reaction 1 :

$$
2 \mathrm{Au}^{+}+\mathrm{HCHO}+3 \mathrm{OH}^{-} \rightarrow \mathrm{HCOO}^{-}+2 \mathrm{H}_{2} \mathrm{O}+2 \mathrm{Au}^{0}
$$

It is evident that high (alkaline) $\mathrm{pH}$ values should favor and accelerate $\mathrm{Au}$ deposition with respect to lower $\mathrm{pH}$ values. If the nuclei start to grow immediately after being randomly formed, their fast growth can cause a fast clogging of the pores.

Note that, for the same composition of the plating bath, the smaller the number of nuclei, the faster they grow. Because of their catalytic role, they act indeed as "attraction points" for the $\mathrm{Au}$ ions present in the same volume of electroless bath enclosed within each single pore.

The present study aims to enhance the insight in these key parameters to optimize the control of the electroless deposition within the template, consequently improving the control on the final morphology of the obtained nanomaterial.

\section{Experimental Section}

Electrochemical Apparatus. All electroanalytical measurements were carried out at room temperature $\left(22 \pm 1{ }^{\circ} \mathrm{C}\right)$ using a threeelectrode single-compartment cell equipped with a platinum coil counter electrode and an $\mathrm{Ag} / \mathrm{AgCl}(\mathrm{KCl}$ saturated) reference electrode. All potential values are referenced to this reference electrode. A CH660A potentiostat controlled via PC by its own software was used for voltammetric measurements. NEEs were assembled from a gold membrane as previously described. ${ }^{1}$

(43) Pereira, F. C.; Moretto, L. M.; De Leo, M.; Boldrin Zanoni, M. V.; Ugo, P. Anal. Chim. Acta 2006, 16, 575.

(44) Paunovic, M.; Schlesinger, M. In Fundamentals of Electrochemical Deposition; Wiley-Interscience Publication: Pennington, NJ, 1998; Chapters 7 and 8, pp 107-160 (Sponsored by The Electrochemical Society, Inc.). 
Microscopy Apparatus. Scanning electron microscopy (SEM) analyses were performed using a JEOL JSM 5600 instrument, while transmission electron microscopy (TEM) measurements were carried out using a JEOL JEM 3010. Images and selected area diffraction (SAD) patterns were taken at $300 \mathrm{kV}$ with ultrahigh resolution pole piece (UHR) with a point to point resolution of $0.17 \mathrm{~nm}$, equipped with a Gatan slow-scan CCD camera (model 794).

Field-emission scanning electron microscopy (FE-SEM) was performed at the Lilit Laboratory, Synchrotron Facility, INFMTrieste-Italy, using a Carl Zeiss 1540XB CrossBeam with a Gemini (SUPRA series) column.

Atomic force microscopy (AFM) analyses were performed using a NTEGRA (NT MDT) microscope with a scanning image processor, SPIP version 4.2, Image Metrology A/S 1998-2005. Measurements were done in contact mode. UV-vis analysis were performed using a Lambda 2 spectrophotometer by Perkin-Elmer.

Plasma Apparatus. Membrane samples were exposed to a $\mathrm{O}_{2} /$ Ar plasma using a Plasma Asher system (EMITECH K1050X) using the following experimental parameters: power, $100 \mathrm{~W} ; \mathrm{O}_{2}$ flow rate $=30 \mathrm{~cm}^{3} \mathrm{~min}^{-1}$; Ar flow rate $=10 \mathrm{~cm}^{3} \mathrm{~min}^{-1}$; and typical etching time $=10 \mathrm{~s}$.

Membranes and Electroless gold Plating. PC filtration membranes (SPI-Pore, $47 \mathrm{~mm}$ filter diameter, $6 \mu \mathrm{m}$ filter thickness) with different nominal pore diameters of 30,100, and $200 \mathrm{~nm}$, coated by the producer with the wetting agent polyvinylpyrrolidone (PVP), were used as the templates to prepare the NEEs. Average pore densities, determined by SEM analyses, were $6.5 \times 10^{8}$ pores $\mathrm{cm}^{-2}$.

Commercial gold electroless plating solution (Oromerse Part B, Technic Inc.) was diluted (40 times with water) prior to use to obtain the typical composition of $7.9 \times 10^{-3} \mathrm{M} \mathrm{Na} 3 \mathrm{Au}\left(\mathrm{SO}_{3}\right)_{2}$ and 0.127 $\mathrm{M} \mathrm{Na}_{2} \mathrm{SO}_{3}$.

The main steps of the "classical" template of the electroless deposition procedure ${ }^{6,18}$ are described below: after wetting for $2 \mathrm{~h}$ in methanol, the PC template membrane was sensitized with $\mathrm{Sn}^{2+}$ by immersion into a solution that was $0.026 \mathrm{M}$ in $\mathrm{SnCl}_{2}$ and 0.07 $\mathrm{M}$ in trifluoroacetic acid in 50:50 methanol-water for $45 \mathrm{~min}$. After rinsing with methanol for $5 \mathrm{~min}$, the sensitized membrane was immersed for $10 \mathrm{~min}$ in $0.029 \mathrm{M} \mathrm{Ag}\left[\left(\mathrm{NH}_{3}\right)_{2}\right] \mathrm{NO}_{3}$. The membrane was then immersed into the Au plating bath containing $0.625 \mathrm{M}$ formaldehyde (procedure for "batch 1"). Alternatively, the formaldehyde was added, in the same amount, only $30 \mathrm{~min}$ after dipping the membrane in the gold electroless bath (procedure for "batch 2").

The temperature of the bath was $0-2{ }^{\circ} \mathrm{C}$. Electroless deposition was allowed to proceed for $15 \mathrm{~h}$, after which an additional $0.3 \mathrm{M}$ formaldehyde was added. Deposition was continued for another $9 \mathrm{~h}$, after which the membrane was rinsed with water and immersed in $10 \% \mathrm{HNO}_{3}$ for $12 \mathrm{~h}$. The membrane was then rinsed again with water and dried at room conditions.

The electroless bath at $\mathrm{pH} 10$ was prepared by adding to the above $0.025 \mathrm{M} \mathrm{NaHCO}_{3}$ and correcting the $\mathrm{pH}$ by dropwise addition of diluted $\mathrm{H}_{2} \mathrm{SO}_{4}$.

Details on further modification of the above-described electroless procedure, used in the present work, are described and discussed in the Results and Discussion section.

Samples preparation. For obtaining dispersion of gold nanoparticles for spectroscopic and HR-TEM studies, membranes were plated for the required time, washed with water, and dried. The outer faces of the membrane were cleaned from outer gold deposit by peeling with scotch tape and/or cleaned with Q-tips embedded with methanol. When required, $\mathrm{PC}$ was dissolved with $\mathrm{CH}_{2} \mathrm{Cl}_{2}$, obtaining stable suspensions of nanoparticles. For UV-vis measurements, the suspensions were introduced directly in the spectrophotometric cuvette. For
HR-TEM measurements, $5 \mu \mathrm{L}$ of the suspension were deposited onto a holey carbon $(\mathrm{Cu})$ grid leaving the solvent to evaporate at room temperature before the analysis.

Chemicals. All chemicals used were reagent grade. (Ferrocenylmethyl)trimethylammonium hexafluorophosphate $\left(\mathrm{FA}^{+} \mathrm{PF}_{6}{ }^{-}\right)$ was prepared as described previously. ${ }^{45}$ Purified water was obtained using a Milli-Ro plus Milli-Q (Millipore) water purification system.

\section{Results and Discussion}

Role of Nuclei Formation. As explained in the Introduction, one possible reason for a poor control on the electroless deposition of gold inside the pores of the template can be the temporal overlap between gold nuclei formation and their growth by formaldehyde addition. To avoid this inconvenience, we tried to separate the nuclei formation step from their following growth process by introducing a delay time between these two steps. This should allow the growth to be started on preformed gold nuclei, with dimensions already larger than the critical size dimension. To test the effect of this procedure, two batches of 30 NEEs each were prepared using a different time span between the moment when the membrane is dipped into the electroless bath and the following formaldehyde addition.

In batch 1, the usual procedure, with no delay time, was used; for batch 2, the delay time was set to $30 \mathrm{~min}$. Deposition and all the following steps were performed according to previous literature reports. ${ }^{6,18}$ The effect of the delay time, in the NEE performances, was checked by examining the cyclic voltammetric behavior of $15 \mu \mathrm{M} \mathrm{FA}^{+}$ $\mathrm{PF}_{6}{ }^{-}$, used as a reversible redox probe of known electrochemical behavior. ${ }^{6}$

Note that the electrochemical behavior of NEEs made of $\mathrm{Au}$ nanodisks as small as $30 \mathrm{~nm}$ is very sensitive to even small defects in the ensemble. ${ }^{1,43}$

Faradic peak current $\left(I_{\mathrm{P}}\right)$, double layer charging current $\left(I_{\mathrm{C}}\right)$, and backward to forward peak separation were obtained by cyclic voltammetry and compared with theoretical values.

The faradic peak current, at an NEE operating in the total overlap regime for a reversible redox system, obeys the Randles-Sevcik equation: ${ }^{6}$

$$
I_{\mathrm{P}}=2.69 \times 10^{5} n^{3 / 2} A_{\text {geom }} D^{1 / 2} C^{*} v^{1 / 2}
$$

where $I_{\mathrm{P}}$ is the peak current (A), $A_{\text {geom }}$ is the overall (nanoelectrodes + insulator between them) geometric area of the ensemble $\left(\mathrm{cm}^{2}\right), D$ is the diffusion coefficient $\left(\mathrm{cm}^{2} /\right.$ $\mathrm{s}), C^{*}$ is the redox species bulk concentration $\left(\mathrm{mol} / \mathrm{cm}^{3}\right)$, and $v$ is the scan rate $(\mathrm{V} / \mathrm{s})$.

At the same NEE, the double-layer charging current $\left(I_{\mathrm{C}}\right)$ is proportional to the area of the electrode elements (i.e., to the active area, $\left.A_{\text {act }}\right):{ }^{46,47}$

$$
I_{\mathrm{C}}=v C_{\mathrm{dl}} A_{\text {act }}
$$

where $C_{\mathrm{dl}}$ is the double layer capacitance of the metal nanodisks of the NEE. Typical $I_{C}$ values for the NEEs used

(45) Lombardo, A.; Bieber, T. I. J. Chem. Educ. 1983, 60, 1080.

(46) Bard, A. J.; Faulkner, L. Electrochemical Methods; Wiley: New York, 2000 .

(47) Greef, R.; Peat, R.; Peter, L. M.; Pletcher, D.; Robinson, J. Instrumental Methods in Electrochemistry; Ellis Horwood Ltd.: Chichester, U.K., 1985. 
Table 1. Comparison of Voltammetric Parameters Obtained with NEEs Prepared in Two Different Batches ${ }^{a}$

\begin{tabular}{lcccc}
\hline & & & $\begin{array}{c}\text { NEEs with } I_{\mathrm{P}} \\
\text { in agreement } \\
\text { with theoretical } \\
\text { values }(\%)\end{array}$ \\
\hline batch 1 & $50 \pm 40$ & $130 \pm 50$ & $89 \pm 23$ & 40 \\
batch 2 & $9 \pm 2$ & $130 \pm 10$ & $68 \pm 6$ & 90 \\
theoretical & 2 & 121 & 59 & \\
value & & & &
\end{tabular}

${ }^{a}$ Batch 1 stands for the literature electroless procedure ${ }^{6}$ and batch 2 for the modified procedure in which formaldehyde was added $30 \mathrm{~min}$ after dipping the membrane in the electroless bath. Experimental conditions for cyclic voltammograms: $15 \mu \mathrm{M} \mathrm{FA}^{+} \mathrm{PF}_{6}^{-}, 10^{-3} \mathrm{M}$ $\mathrm{NaNO}_{3}, A_{\text {geom }}=0.07 \mathrm{~cm}^{2}$, scan rate $0.05 \mathrm{~V} \mathrm{~s}^{-1}$. Additional parameters used for theoretical value calculations: $C_{\mathrm{dl}}=40 \mu \mathrm{F} / \mathrm{cm}^{2}, D=4 \times 10^{-6}$ $\mathrm{cm}^{2} \mathrm{~s}^{-1} \cdot 1,6 I_{\mathrm{C}}$ are the capacitive currents measured in pure supporting electrolyte: theoretical value calculated by eq 3 using $A_{\text {act }}=8 \times 10^{-4}$ $\mathrm{cm}^{2} ; I_{\mathrm{P}}$ are the oxidation peak currents of $\mathrm{FA}^{+}$: theoretical value calculated by digital simulation; $\Delta E_{\mathrm{P}}$ is the difference between forward and backward peak potentials; $\%$ is calculated respect to a number of 30 NEEs in each batch; errors are estimated as one standard deviation.

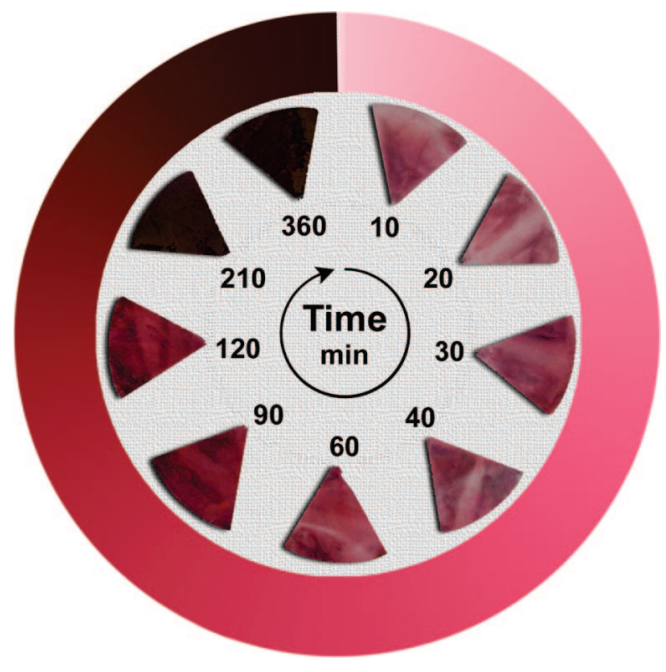

Figure 1. Photograph of the PC membranes (200 nm pore diameter) plated at $\mathrm{pH} 10$ in a gold electroless bath containing $0.625 \mathrm{M}$ formaldehyde, using different dipping times: 10, 20, 30, 40, 60, 90, 120, 210, and $240 \mathrm{~min}$ in the clockwise direction from the arrow.

in this work should be around $1 \mathrm{nA}$ (based on a $C_{\mathrm{dl}}$ value between 20 and $40 \mu \mathrm{F} \mathrm{cm}{ }^{-2}, 47$ a gold NEE with $A_{\text {geom }}=$ $0.079 \mathrm{~cm}^{2}$, pore density $=6 \times 10^{8}$ pore $/ \mathrm{cm}^{2}$, average pore radius $=2 \times 10^{-6} \mathrm{~cm}$, and scan rate $\left.(v)=0.05 \mathrm{~V} / \mathrm{s}\right)$, while $I_{\mathrm{P}}$ values for $15 \mu \mathrm{M} \mathrm{FA}^{+}$are around $120 \mathrm{nA}$.

From a practical viewpoint, the values recorded at $50 \mathrm{mV} / \mathrm{s}$ for the faradic peak currents and for the double layer charging currents calculated by eqs 2 and 3 can be used to discriminate between "good" and "bad" NEEs, the latter being NEEs with some defect which causes their voltammetric signals to differ from the expected ones.

Table 1 lists and compares these data. Experimental $I_{\mathrm{P}}$ and $I_{\mathrm{C}}$ values are averaged over the 30 NEEs of each batch, and their standard deviations may be taken as an indicator of the "goodness" of the batch.

From Table 1, it is evident that the introduction of a delay time of $30 \mathrm{~min}$ between dipping the activated membranes in the electroless bath and adding formaldehyde lowers the standard deviations, both in $I_{\mathrm{P}}$ and $I_{\mathrm{C}}$ values, and the percentage of "good" NEEs increases from $40 \%$ to $90 \%$. Furthermore, when the $30 \mathrm{~min}$ delay time is adopted, the

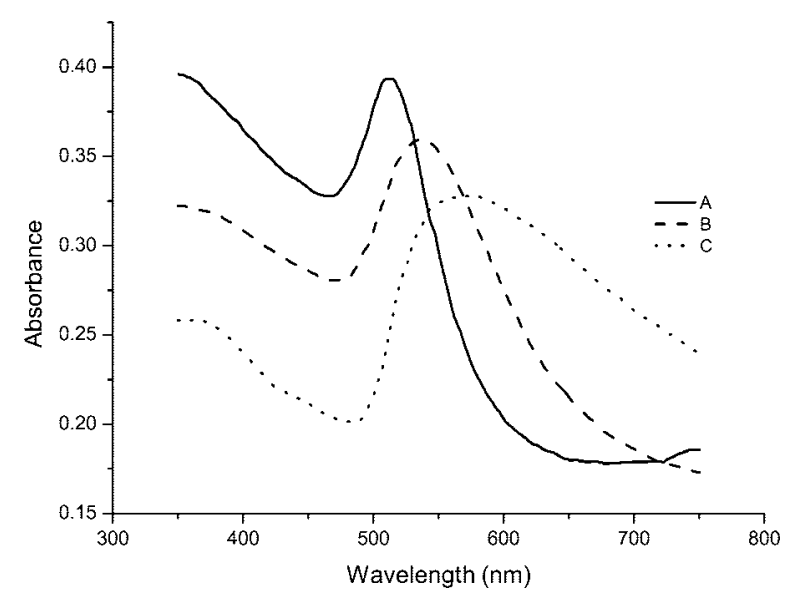

Figure 2. UV-vis absorption spectra of $\mathrm{CH}_{2} \mathrm{Cl}_{2}$ suspensions of $\mathrm{Au}$ nanoparticles prepared in PC membranes with pore diameters of $30 \mathrm{~nm}$ (curve A), $100 \mathrm{~nm}$ (curve B), and $200 \mathrm{~nm}$ (curve C). The membranes were dissolved with $\mathrm{CH}_{2} \mathrm{Cl}_{2}$ as described in the text.

capacitive current (obtained as half of the difference between forward and backward current in pure supporting electrolyte) is notably lower. This evidence confirms the key role of achieving the full completion of nucleation before starting their growth process.

Influence of the Deposition pH on Optical Properties. In a series of experiments, we performed electroless deposition of gold in PC membranes with a pore diameter of $200 \mathrm{~nm}$ changing either the plating time or the $\mathrm{pH}$ values but using the "batch 1" procedure. Figure 1 shows the macroscopic aspect of PC membranes plated at $\mathrm{pH} 10$ using different deposition times. Because these tests were performed with no delay time before adding formaldehyde, time zero corresponds to the instant when the membrane is dipped in the gold electroless bath.

Depending on the deposition time, the samples presented different colors ranging from a light pink (10 min) to a deep purple (120 min) as long as gold particles were deposited mainly within the pores. After $210 \mathrm{~min}$, a thin massive blackish-golden layer deposited on the surface of the membrane was observed. The pink and purple colors are due to the plasmon resonance of the gold nanoparticles formed within the pores at short deposition time. These particles absorb light in the visible, with a maximum wavelength which depends on the particle size. ${ }^{48,49}$ Smaller particles absorb mainly at $520 \mathrm{~nm}$ and appear pink. ${ }^{30}$

The comparison of the macroscopic aspect of two membranes withdrawn from the electroless bath at the same time (namely, $30 \mathrm{~min}$ ) but at different $\mathrm{pH}$ values, namely, $\mathrm{pH} 10$ and 12 reveals a pink color for the former case versus a blackish color for the latter (not shown).

Figure 2 shows the UV-vis adsorption spectrum obtained from $\mathrm{CH}_{2} \mathrm{Cl}_{2}$ dispersion of $\mathrm{Au}$ nanoparticles obtained by electroless deposition in track-etched membranes with pore diameters of 10,30 , and $200 \mathrm{~nm}$ (curves $\mathrm{A}, \mathrm{B}$, and $\mathrm{C}$ respectively). The spectral characterization of these $\mathrm{CH}_{2} \mathrm{Cl}_{2}$ suspensions agrees with those of gold nanowires of high

(48) Tian, M. L.; Wang, J. G.; Kurtz, J.; Mallouk, T. E.; Chan, M. H. W. Nano Lett. 2003, 3, 919.

(49) Foss, J. C. A.; Hornyak, G. L.; Stockert, J. A.; Martin, C. R. J. Phys. Chem. 1994, 98, 2963. 

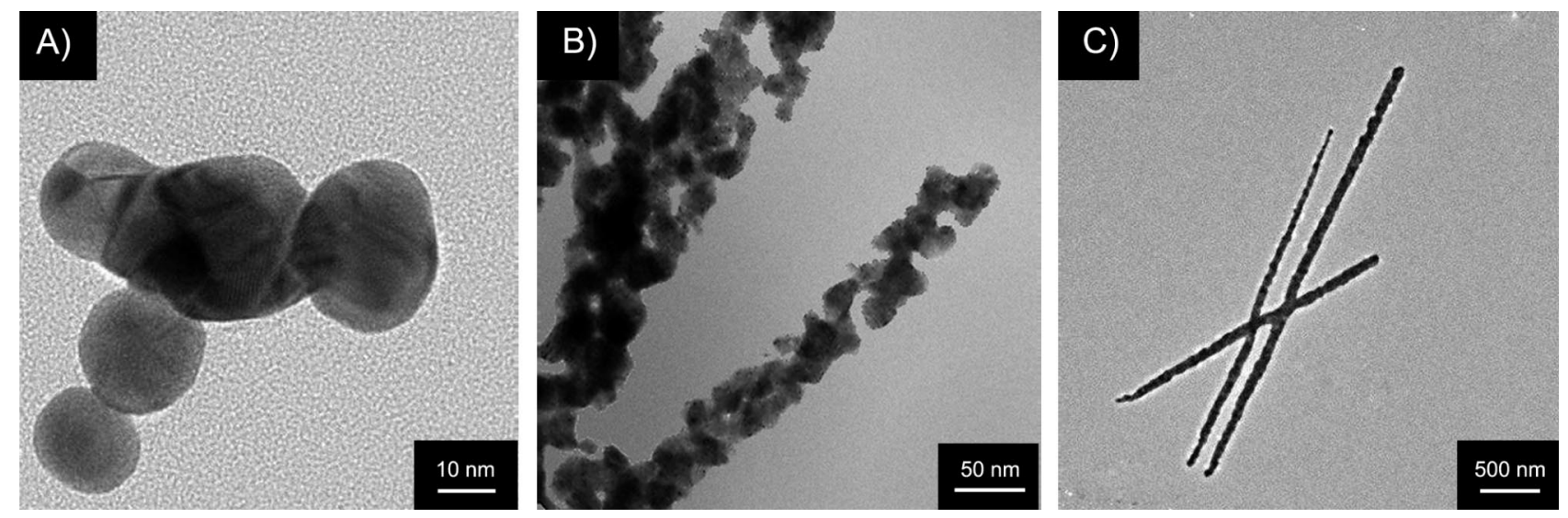

Figure 3. HR-TEM (A, C) and TEM (B) images of Au nanoparticles produced by electroless deposition, separated after dissolving the PC membrane (30 nm pore diameter) with $\mathrm{CH}_{2} \mathrm{Cl}_{2}$. Gold plating time: $10 \mathrm{~min}(\mathrm{~A}), 30 \mathrm{~min}(\mathrm{~B})$, and up to $24 \mathrm{~h}(\mathrm{C})$ at $\mathrm{pH} 12$.

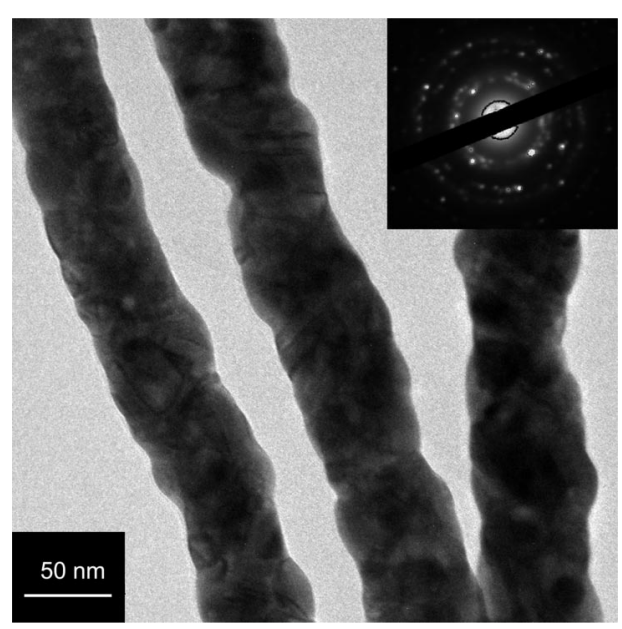

Figure 4. HR-TEM image of templated Au nanofibers plated for $24 \mathrm{~h}$. Inset: SAD pattern confirms their polycrystalline structure. Other parameters as in Figure 3.

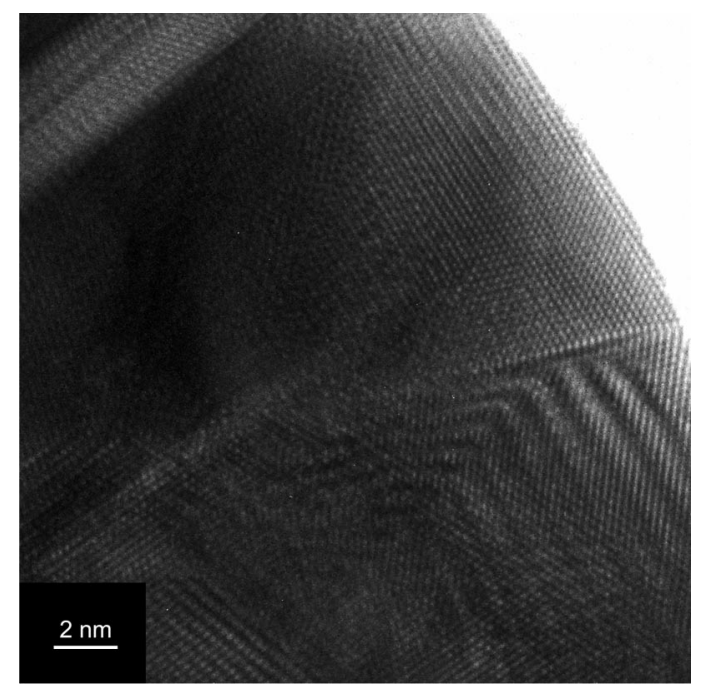

Figure 5. HR-TEM image of a zone with boundaries between differently oriented crystals in a templated Au nanofiber.

aspect ratio, both embedded in templates ${ }^{49}$ and in water dispersion. ${ }^{38}$

Values of $\lambda_{\max }$ display a red shift with increasing pore diameter ${ }^{50,51}$ and, in the vis region, transversal resonance is the dominating resonance mode. Note that the absorption
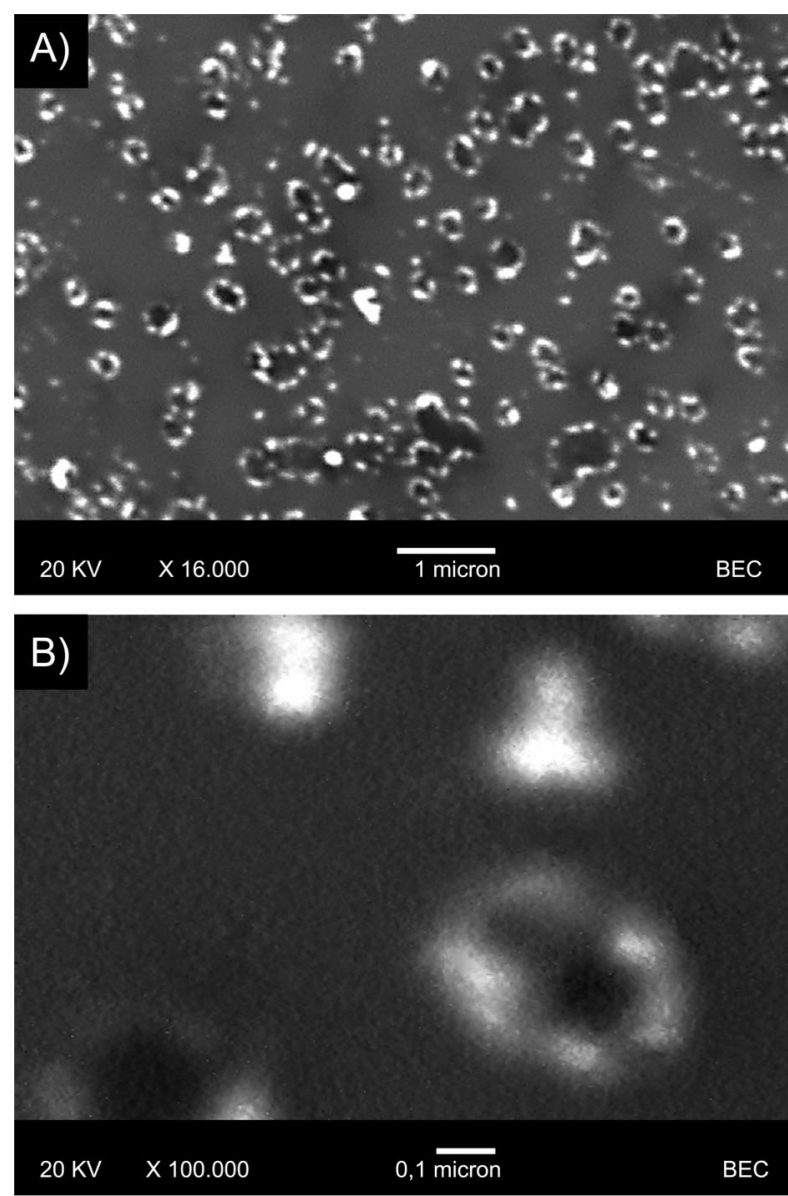

Figure 6. (A): SEM image of the surface of a template $(200 \mathrm{~nm}$ pore diameter) after gold electroless deposition for $40 \mathrm{~min}$ at $\mathrm{pH}$ 10. (B) Zoom in.

band due to the longitudinal resonance ${ }^{52}$ is not observable with our nanoparticles, because they have an aspect ratio from 30 to 600 .

Electron Microscopy. A first study on the nucleationgrowth of the gold particles in the template was performed by HR-TEM analysis on samples obtained at $\mathrm{pH} 12$ with different plating time. Note that in these experiments,

(50) Okamoto, T.; Yamaguchy, I. J. Phys. Chem. B 2003, 107, 10321.

(51) Xu, H.; Käll, M. Sens. Actuators B 2002, 87, 244.

(52) Link, S.; Mohamed, M. B.; El-Sayed, M. A. J. Phys. Chem. B 1999, 103,3073 . 

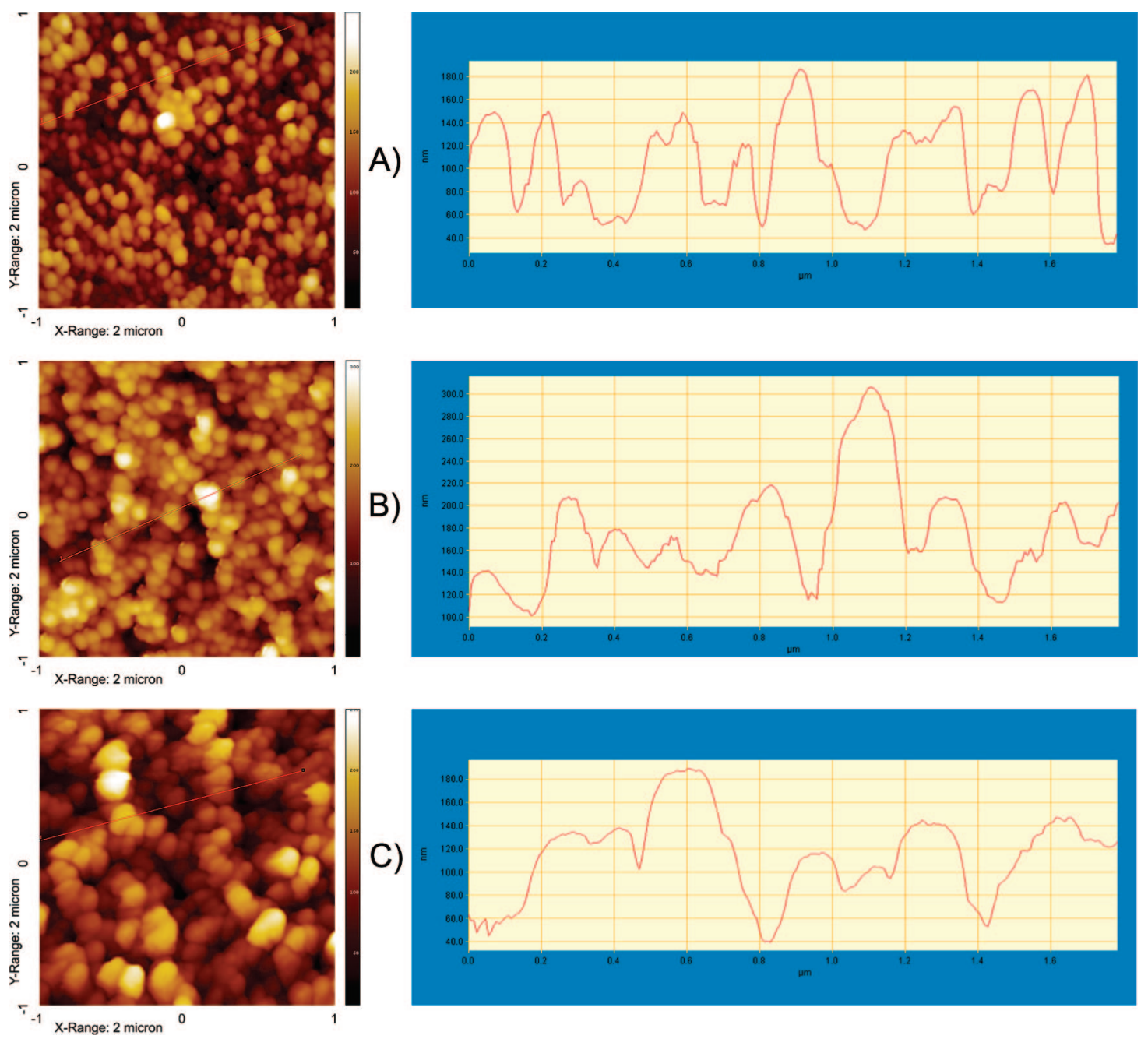

C)

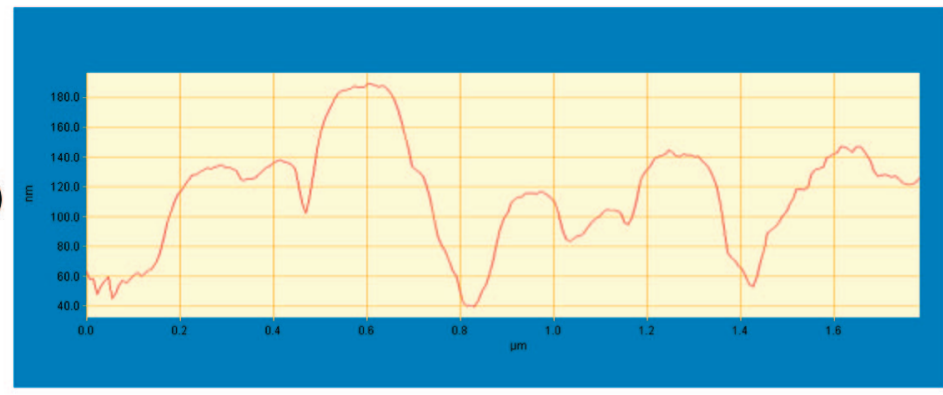

Figure 7. Dependence of the surface roughness on $\mathrm{pH}$ values. On the left: AFM image of the outer surface of the template ( $30 \mathrm{~nm}$ pore diameter) after gold electroless deposition for $24 \mathrm{~h}$ at (A) $\mathrm{pH} 7$, (B) $\mathrm{pH} \mathrm{9,} \mathrm{and} \mathrm{(C)} \mathrm{pH} 10$. On the right: distribution of the density of the summit.

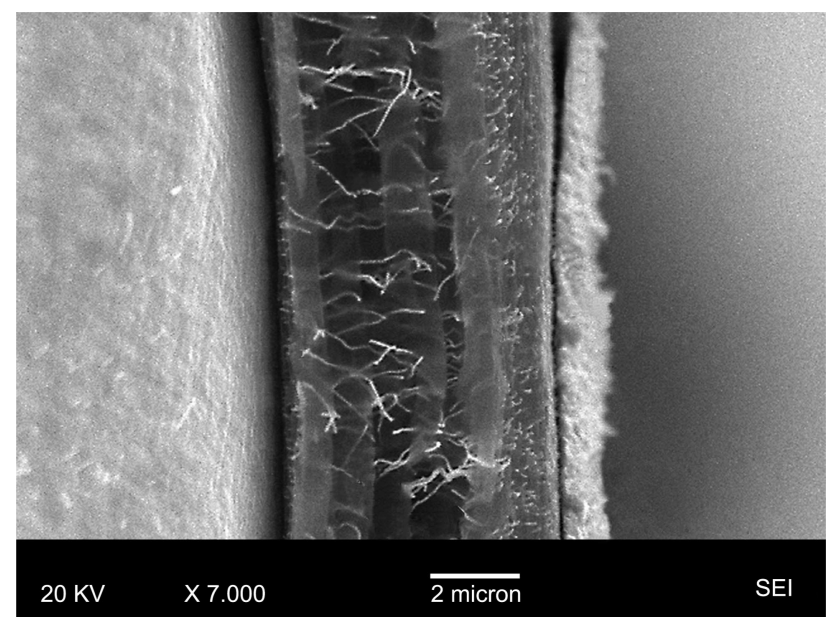

Figure 8. SEM image of the cross section of the PC template $(30 \mathrm{~nm}$ pore diameter) after gold electroless deposition for $24 \mathrm{~h}$ at $\mathrm{pH} 12$.

performed on templates with $30 \mathrm{~nm}$ pore diameter, the electroless plating solution and formaldehyde were added simultaneously, according to the classical electroless procedure. In particular, analysis were performed by sampling

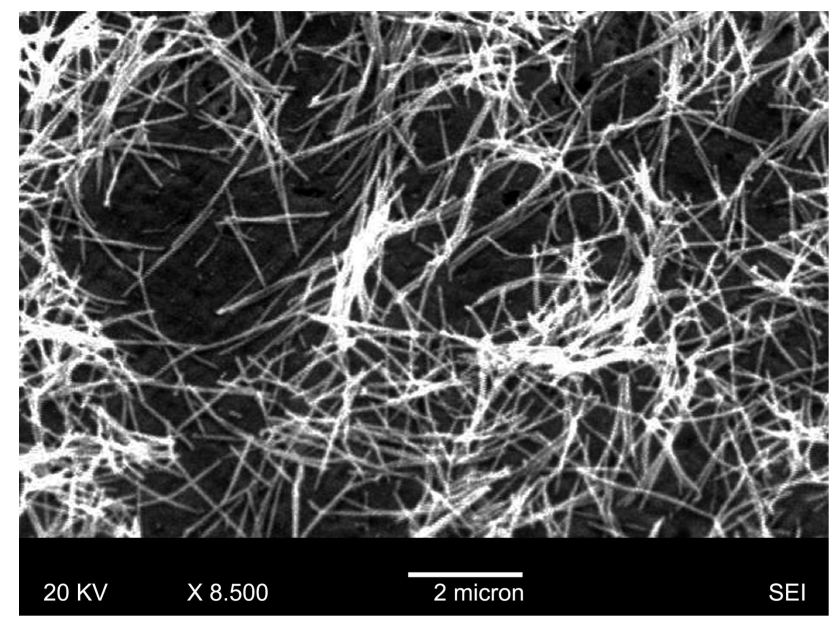

Figure 9. SEM image of the Au nanofibers obtained with PC membrane (30 $\mathrm{nm}$ pore diameter), after gold electroless deposition, for $24 \mathrm{~h}, \mathrm{pH} 12$, followed by removal of the outer gold deposit and dissolution of PC with $\mathrm{CH}_{2} \mathrm{Cl}_{2}$.

small pieces of the membranes plated for $10 \mathrm{~min}$, one hour and $24 \mathrm{~h}$ after formaldehyde addition to the electroless plating bath. 

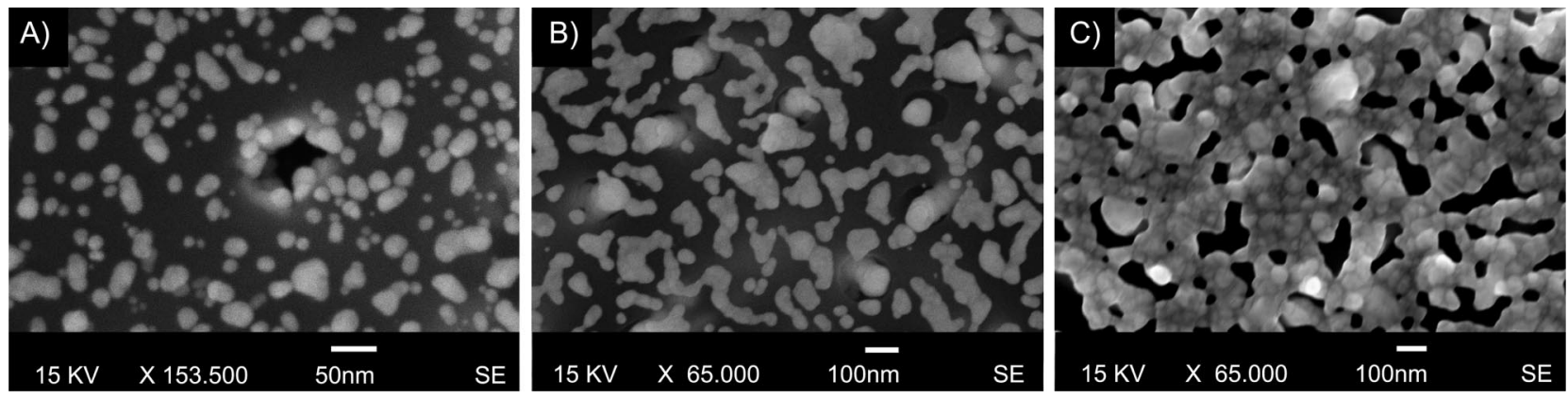

Figure 10. FE-SEM images of the PC membrane with $100 \mathrm{~nm}$ pore diameter after gold electroless deposition at $\mathrm{pH}$ 12. Samples examined after different gold plating times: (A) $10 \mathrm{~min}$, (B) $30 \mathrm{~min}$, and (C) $60 \mathrm{~min}$.
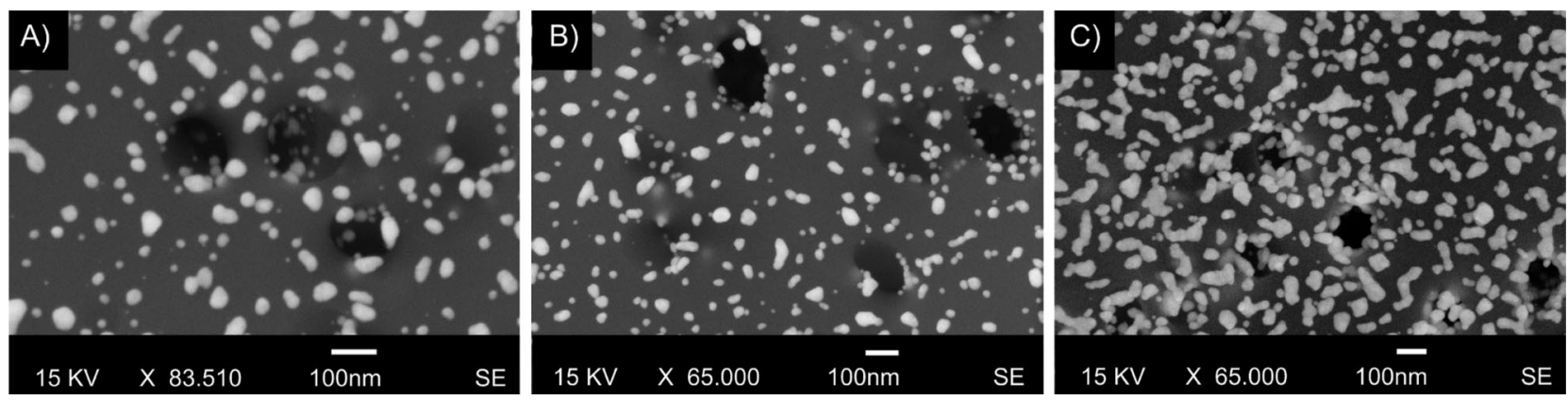

Figure 11. FE-SEM images of the PC membrane with $100 \mathrm{~nm}$ pore diameter after gold electroless deposition at pH 10. Samples examined after different gold plating times: (A) $70 \mathrm{~min}$, (B) $120 \mathrm{~min}$, and (C) $150 \mathrm{~min}$.

TEM and HR-TEM images evidenced that roundish gold nanoparticles of approximately $10 \mathrm{~nm}$ in diameter are obtained after a short deposition time (Figure 3A). These particles are already stable, and their size exceeds the critical nuclei size,${ }^{44}$ because they are generated by redox reaction between $\mathrm{Au}(\mathrm{I})$ ions and silver nanoparticles generated during the activation step. The gold particles start to be linked together at longer deposition time (Figure 3B) until they eventually give rise to continuous nanofibers (Figure 3C). The latter appears slightly cigar-like shaped, as previously observed, ${ }^{36,53}$ as a consequence of the shape of the pores in this kind of template. The average diameters of the central (thicker) part of these fibers are in the 60-75 $\mathrm{nm}$ range, which is greater than the nominal pore diameter in the original membrane $(30 \mathrm{~nm})$. However, these fibers narrow toward their tips, where they approach diameters of about $50 \pm 10$ $\mathrm{nm}$, which are closer to the nominal pore diameters.

Figure 4 suggests again that nanorods do not build up layer-by-layer from the membrane walls but rather develop from single Au nuclei as separate rounded particles, which then grow and eventually merge into a single elongated particle. In fact, the rough surface and the granular inner structure indicate that these long fibers are actually built up by connected particles.

SAD patterns (see the inset in Figure 4) further confirm this view showing that the long fibers are made up of several differently oriented crystals. The rounded building blocks themselves are only seldom single crystals; on the contrary, they usually show a complex polycrystalline structure, which suggests that they have initiated from different Au nuclei, probably even on opposite sites of the pore walls, which then

(53) Ugo, P.; Pepe, N.; Moretto, L. M.; Battagliarin, M. J. Electroanal. Chem. 2003, 51, 560. merged together. HR-TEM shows (Figure 5) that boundaries between differently oriented crystals, both inside the rounded particles and, in the longer rods, between them, are highly defective.

As for nanotubes, Martin and co-workers obtained such structures at short deposition time; however, apart the first paper for the fabrication of Au nanotubes, ${ }^{6}$ Martin's group adopted later, for nanotube preparation, a $\mathrm{pH} \leq 10 .^{41}$ This prompted us to study in more detail the $\mathrm{pH}$ influence.

Typical SEM images obtained on membranes, with pore diameters of $200 \mathrm{~nm}$, plated for $40 \mathrm{~min}$ at $\mathrm{pH} \mathrm{10}$, are shown in Figure 6. In spite the low resolution, gold rings, with thickness between 60 and $80 \mathrm{~nm}$, are visible around the aperture of each pore, suggesting the presence of gold nanotubes inside. At $\mathrm{pH} 12$ for the same deposition time, such tubular structures could not be found.

AFM was used to analyze the morphology of the gold layer deposited on the surface of the template; plating was carried out for $24 \mathrm{~h}$ at three different $\mathrm{pH}$ values, namely, $\mathrm{pH} 7,9$, and 10. AFM images in Figure 7 indicate that grain size and surface roughness increased with the $\mathrm{pH}$ of the electroless bath. Note that all images have the same scale to allow one to make an easy comparison between the different surface roughnesses.

These results agree with the expectation, based on eq 1 , that the deposition kinetics becomes progressively faster by increasing the $\mathrm{pH}$ of the bath. This reflects a higher roughness of the deposit obtained at more alkaline $\mathrm{pH}$, although the number of peaks per section length remains roughly constant.

Figure 8 shows the SEM image of a cross section of the $\mathrm{PC}$ membrane after gold deposition at $\mathrm{pH} 12$. This particular sight allows one to see the Au-filled pores. Note that the section is slightly tilted with respect to the SEM detector so 

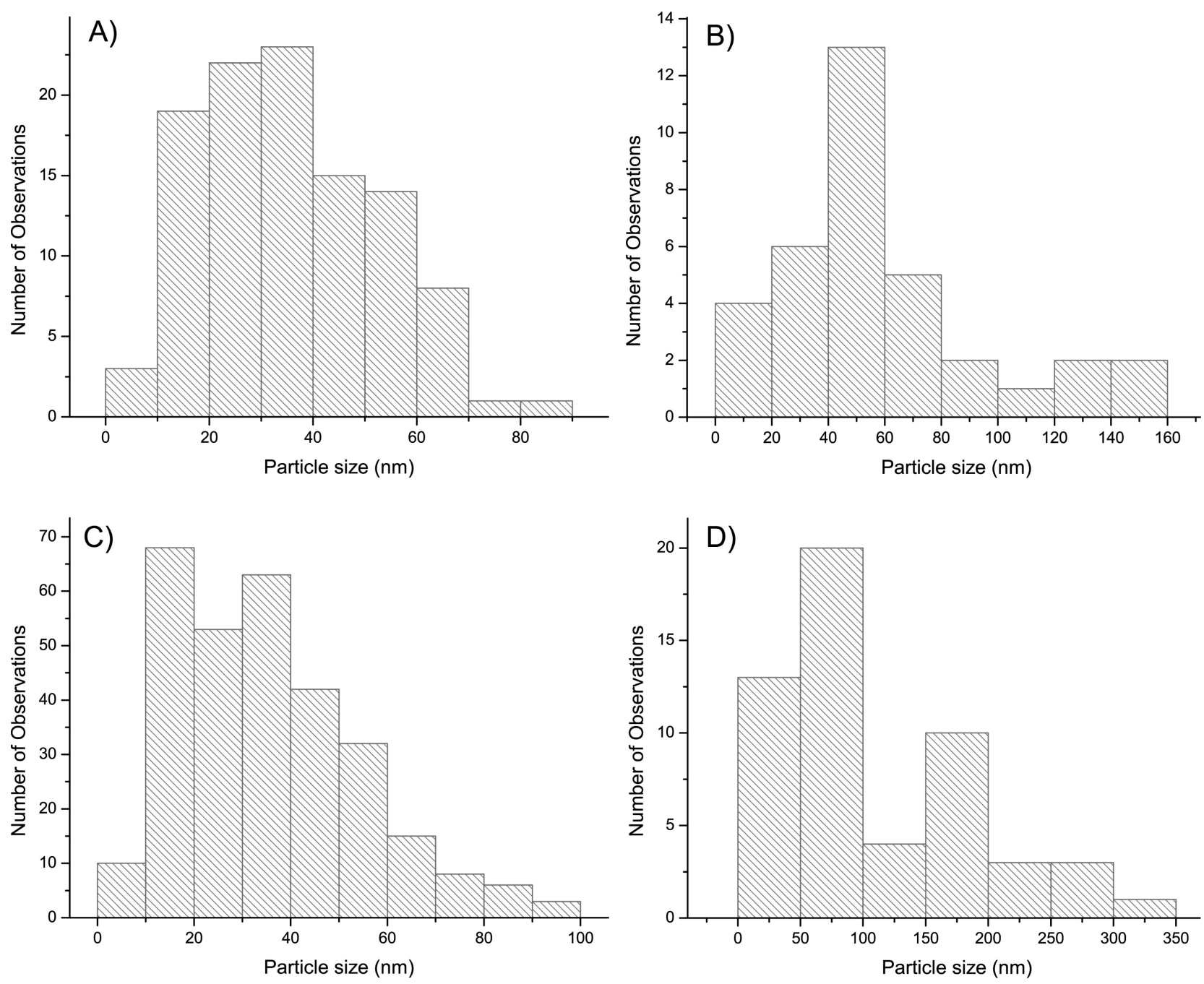

Figure 12. Size distribution of the deposited particles in a membrane with $100 \mathrm{~nm}$ pore diameter, via electroless procedure at (A, B) $\mathrm{pH} 10$ for 70 and 150 min and $(\mathrm{C}, \mathrm{D}) \mathrm{pH} 12$ for 10 and $30 \mathrm{~min}$.

Table 2. pH and Time Influence on the Size and Spatial Distribution of Au Nanoparticles during the Electroless Deposition Procedure $^{a}$

\begin{tabular}{lccccc}
\hline & $\begin{array}{c}\text { average } \\
\text { particle } \\
\text { diameter } \\
(\mathrm{nm})\end{array}$ & $\begin{array}{c}\text { number of } \\
\text { particles per } \\
\text { unit } \\
\text { surface }\end{array}$ & $\begin{array}{c}\text { average } \\
\text { particle } \\
\text { distance } \\
(\mathrm{mm})\end{array}$ & $\begin{array}{c}\text { \% of } \\
\text { coverage }\end{array}$ \\
\hline $\mathrm{pH} \mathrm{10}$ & 70 & 39 & 123 & 97 & 16 \\
& 150 & 62 & 96 & 110 & 38 \\
$\mathrm{pH} \mathrm{12}$ & 10 & 39 & 202 & 78 & 43 \\
& 30 & 120 & 27 & $b$ & 50
\end{tabular}

${ }^{a}$ Modified electroless procedure with the delay time of 30 min. ${ }^{b}$ Not applicable because particles start to coalesce.

that the outer gold layer is visible only on the right-hand side of the image. The thickness of the membrane is equal to $6 \mu \mathrm{m}$, while the average thickness of the outer gold deposit is $1 \mu \mathrm{m}$. The nanofibers, grown inside the membrane, are not aligned parallel but have a considerable angular distribution. This is a consequence of the angles of the original trajectories of the tracks used to sensitize the membrane before etching of the pores in the membrane production. ${ }^{33,53}$

However, some distortion and artifacts are evident from this image where apparent whirling and bending of the fibers are observed; this is attributable to possible interactions between the e-beam and the polymer. ${ }^{53}$ In fact, after removing the PC membrane by dissolution with $\mathrm{CH}_{2} \mathrm{Cl}_{2}$, perfectly straight nanofibers are observed as shown in Figure 9.

To get more precise information on the $\mathrm{pH}$ influence specifically on the growth of the nuclei, a series of analyses by FE-SEM were performed. Note that the higher resolution of FE-SEM is expected to allow a deeper insight than SEM into the morphology of the deposit; moreover, it does not require the complex sample treatment necessary to perform HR-TEM.

To focus on the growth kinetics only, the nucleation and growth were kept separated, as described for "batch 2". Samples were taken at different times, considering time zero as the time when formaldehyde was added; as a consequence of the faster deposition kinetics, samples at $\mathrm{pH} 12$ were analyzed after plating time shorter than at $\mathrm{pH} 10$. The PC membrane had $100 \mathrm{~nm}$ pore diameters.

Figure 10A-C shows typical FE-SEM of samples plated at $\mathrm{pH} 12$, for 10, 30, and $60 \mathrm{~min}$, respectively. Figure 11A-C reports the results at $\mathrm{pH} 10$ with plating times of 70,120 , and $150 \mathrm{~min}$.

Figure 12 reports the size distribution of the deposited particles, obtained by image analyses, while Table 2 lists relevant parameters concerning particle size and their surface 

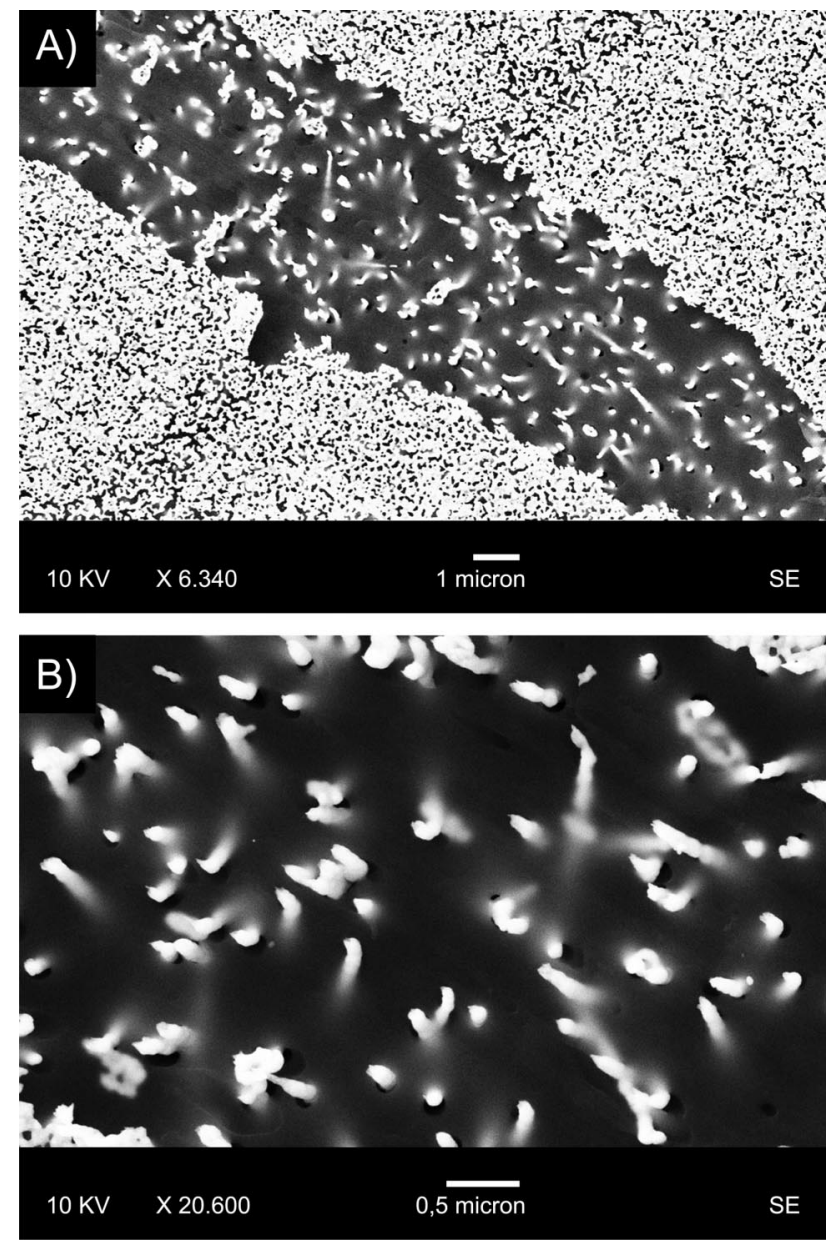

Figure 13. (A) FE-SEM images of the PC membranes $(100 \mathrm{~nm}$ pore diameter) after $60 \mathrm{~min}$ of gold electroless deposition at $\mathrm{pH} 12$. The central zone of the sample is peeled from outer Au coating and etched with oxygen/ argon plasma for $10 \mathrm{~s}$. (B) Zoom in of the peeled area.

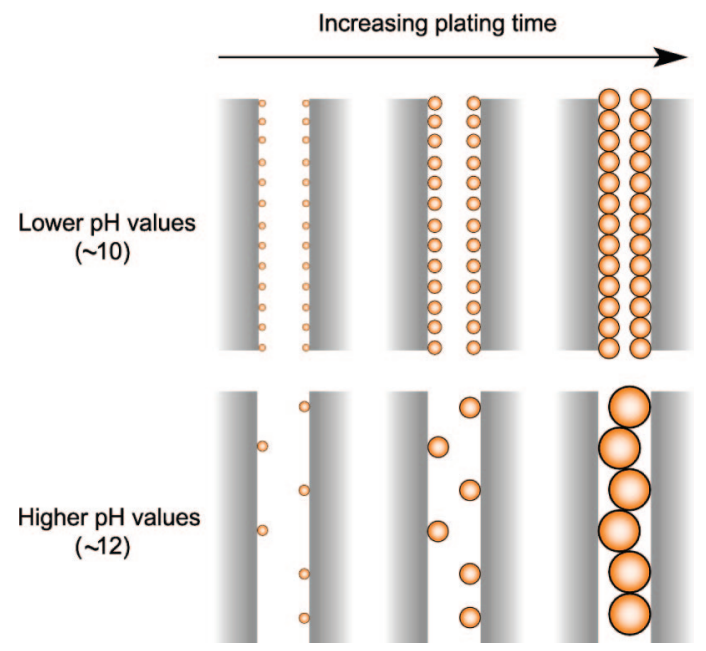

Figure 14. Qualitative sketches of the particle growth within pores with diameter approximately equal to $30 \mathrm{~nm}$ : comparison of the situation at $\mathrm{pH}$ 10 and $\mathrm{pH} 12$ after a few minutes (on the left), $0.5-1 \mathrm{~h}$ (in the middle), and $2-5 \mathrm{~h}$ (on the right).

distribution. The average diameter at $\mathrm{pH} 10$ and $70 \mathrm{~min}$ compares with the one at $\mathrm{pH} 12$ and $10 \mathrm{~min}$, however with a larger number of particles per unit surface. This confirms the faster deposition at the latter $\mathrm{pH}$. Comparison of size distribution for these two depositions indicated a narrower range at $\mathrm{pH} 10$. Interestingly, the average particle diameter is never smaller than about $40 \mathrm{~nm}$, independent of $\mathrm{pH}$. This is explained by the fact that during the delay time, before formaldehyde addition, the gold nuclei quickly grow well above their critical size (see also Figure $3 \mathrm{~A}$ ) via reaction between $\mathrm{Au}(\mathrm{I})$ and silver nanoparticles. At variance with reaction 1, the electron exchange between $\mathrm{Ag}^{0}$ and $\mathrm{Au}(\mathrm{I})$ does not depend on the solution $\mathrm{pH}$.

At $\mathrm{pH}$ 12, for time longer than $10 \mathrm{~min}$, particles already start to coalesce. The high resolution of FE-SEM allowed us to focus on the particle growth inside the pores. At $\mathrm{pH}$ 10 , after $10 \mathrm{~min}$ of plating, some particles can be imaged inside the pores (Figure 11A), their number growing with plating time, until, after $150 \mathrm{~min}$, the pore walls are coated by a tubular assembly of Au particles (Figure 11C). At pH 12 , a similar situation is observed at a much shorter time, namely, 10 min (Figure 10A).

Figure 13 shows the detail of the membrane plated at $\mathrm{pH}$ 12 for $60 \mathrm{~min}$. For obtaining these images, the outer gold deposit was peeled from the plated membrane, and the membrane was slightly etched with oxygen-plasma. This procedure removes a few nanometers of the outer PC layer and causes, by local heating around the metal fiber, the enlargement of the pore diameter ${ }^{20}$ so that the structure inside the pores can be partially imaged; the formation of continuous fibers is evidenced by these analysis.

All this evidence suggests that, once the nucleation step is well separated from the following growth, what is more strongly influenced by the $\mathrm{pH}$ is the kinetics of the growth of these nuclei so that at $\mathrm{pH} 12$ full fibers are formed very quickly $(60 \mathrm{~min})$, with a hollow gold nanotube being detectable only in the first minutes of the plating. On the contrary, at $\mathrm{pH} 10$, the growth is very slow and more controlled, so that the result after $150 \mathrm{~min}$ at $\mathrm{pH} 10$ compares roughly with the one obtained after only $10 \mathrm{~min}$ at $\mathrm{pH} 12$ (compare Figures 11C and 10A).

\section{Conclusions}

The results obtained by a variety of characterization techniques, at different deposition times and $\mathrm{pH}$ values, indicate that gold deposition in templates of small diameter (approximately equal to $30 \mathrm{~nm}$ ) can be summarized by the sketch in Figure 14.

At $\mathrm{pH} 10$, smaller grain size and smaller roughness are indicative of a slower growth of the gold nanoparticles. Note that the growth process of each nucleus is slowed down by the presence of a large number of nuclei which all consume the diffusing $\mathrm{Au}(\mathrm{I})$ ions. This explains why at short time nanotubes can be formed (Figure 6).

On the contrary, at higher $\mathrm{pH}$ values, such as $\mathrm{pH} 12$, the growth kinetic is accelerated. This reflects in the fast growth of gold particles which are bound together producing (under small pore diameter constraints) nanofibers composed, however, by aggregates of Au particles, as evidenced by the HR-TEM observations reported in Figure 3. Analyses of the dimension of deposited Au particles indicate that particles with diameter exceeding $30 \mathrm{~nm}$ are quickly formed. Even if sometimes, at very short time, particles as small as $10 \mathrm{~nm}$ 
can be formed (see Figure 3A), it seems very difficult to control so tightly the process to obtain tubular structures in pores with diameters smaller than $30 \mathrm{~nm}$.

From a strictly practical viewpoint, we can conclude that $\mathrm{pH} 10$, or even lower, is to be preferred when nanotubes are the desired final product of the template deposition, while pH 12 can be the right choice when one wishes to quickly obtain continuous nanofibers. For templates with pore diameter of $100 \mathrm{~nm}$ or larger, gold nanotubes can be formed even at pH 12 but, again, only at very short deposition time.

With the electroless procedure developed here, poly- crystalline structure was always observed, indicating that different methods must be applied to obtain single crystal nanowires.

Acknowledgment. We wish to thank Federica Minto and Andrea Mardegan (University of Venice), Massimo Tormen and Alessandro Carpentiero (TASC-CNR-INFM, Trieste), and Piero Schiavuta (CIVEN, Venice) for skillful assistance in some of the experiments. Financial support by MUR (Rome, Cofin 2006) is gratefully acknowledged. 